\title{
Reliability Analysis of Port Harcourt Network in the Presence of Distributed Generation
}

\author{
Ajabuego O. G \\ Electrical Engineering Department, \\ University of Port Harcourt, Port Harcourt, \\ Rivers state, Nigeria
}

\author{
Uzoechi L. O \\ Electrical \&Electronic Engineering Department, \\ Federal University of Technology, Owerri, \\ Imo state Nigeria
}

\begin{abstract}
Reliability study is done in this paper for effective planning of the Port Harcourt Network. This study is done considering the voltage profile, real and reactive power sensitivity in the Network. The parameters considered are the Voltage Profile Improvement Index (VPII), Real and Reactive Power Improvement Index (ILP and ILQ). From the result gotten, the performance of the Network is best when 13 DGs which are obtainable in Port Harcourt are attached to the Network. This shows best results in the three parameter considered in this work. Only the best placement sensitivity result is shown in this work for each of the placement of the DGs. After the study it was observed that it will be proper for the DGs to be place at PH Z2, PH Z, TIA Z2, T2A Z2, T3A Z2, TIB Z4, TIA Z4, T2A Z4, Rumuodomaya, Rumuola feeder, Oyigbo, Trans-Amadi and Onne feeder for better performance
\end{abstract}

Keyword: Reliability, Profile, Parameter, Port Harcourt, Distributed Generation,

\section{INTRODUCTION}

Since the integration of Distributed Generation (DG), it has increased to a high penetration level, and the impact of DGs on the voltage stability margin and the frequency has become significant, it will be wise to investigate its impact on the Nigeria network. To achieve this, a subsection of the network is considered to see the effect of the penetration of the DG in both the centralized grid and using it as off grid electrification (cutting out some lines in that grid and just supplying them with the DG). The network considered is the Port Harcourt network. Port Harcourt (PH) is situated in the south-south geo-political zone in Nigeria. Port Harcourt, though a small town, its network was chosen due to the high industrialization and the increasing demand of electricity by these industries in this area. Major industries like the oil industries with high electricity consuming equipments are found in this area of Nigeria. It shows that there is every tendency for the electricity consumption or demand of the area to double the actual demand in few years to come. The Port Harcourt network comprise of 69 buses of distribution along the south-south location in the Nigerian map. It gets supply basically from Afam and Ahoada which is about 220MVA (176MW) of power supply which is not enough to stabilize the demand of the state. The estimated load demand of Port Harcourt is $400 \mathrm{MW}$ [1], and the ongoing works in the state is how to use the large gas turbine (DG) generators to stabilize the demands of power in the state. At Omoku, power plant, there are six gas turbines which generates $25 \mathrm{MW}$ of power each (total of $150 \mathrm{MW}$ of power generation), and at Transamadi, 4 gas turbines generating 25MW and 3 gas turbines generating $10 \mathrm{MW}$ of power (total of 130MW of generation). The total power to be realized from the ongoing reforms is $280 \mathrm{MW}$ of power to boost the existing $176 \mathrm{MW}$ of power. The problem arising is how to maintain the DGs and also dispatch it effectively. To maintain and dispatch the DGs effectively, it will be proper to know how reliable the DGs are to voltage sensitivity, real and reactive power sensitivity. This is the main focus of this research. The reliability of the network is investigated in this work to enable the Network planner consider the best approach in designing the DGs in the Network

\section{REVIEW OF LITTERATURES}

The authors of [2] presented the methods of data collection to calculate the reliability indices of system. The paper talks about classes of customers, selecting the relevant index, outage data collection such as the indices reflect the actual customer perceptions and hence would contribute towards improving the reliability. In [3], the author presented a survey of the reliability indices practices in the US. The results showed that SAIDI (System Average Interruption Duration Index), SAIFI (System Average Interruption Frequency Index ), CAIFI (Customer Average Interruption Frequency Index) and ASAI (Average Service Availability Index) were the most used indices. The paper also discussed outage factors and their roles in reliability calculation. The calculation of reliability indices can be examined by using developed softwares.

In [4], the authors used a test system on a General reliability program DISREL (Distribution System Reliability Evaluation) to show the impact of distributed generation improving the reliability of the system. The paper showed that DG was a cost-effective solution that could benefit both utility and customers. The authors in [5] presented modeling techniques for DG, and apply them to a radial network using commercial software tools that show improvement in the reliability indices. Several papers have presented techniques to evaluate the reliability of the system. In [6], the author presented an analytical approach to calculate the reliability of the system that included some intrinsic attributes of the DG and the distribution system including DG failure, component failure, change in load demand etc. Many factors were considered for the 
reliability indices calculation in the proposed technique. In [7], the author presented an analytical and probabilistic approach to calculate the reliability for momentary interruptions. The paper also presented reliability cost evaluation technique that unifies sustained and momentary interruptions costs.

The location for the placement of DGs is of key importance. In [8], the authors studied the effects of DG on system reliability on an Iranian Distribution system. The analysis showed that reliability indices were highly sensitive to location. In [9], the authors discussed the DG impacts on reliability, losses and voltage profile of the system. The paper showed that reliability indices could be improved by properly allocating DG. Properly coordinated distributed generation can have a positive impact on the system.

[10] presented the positive and negative impact of DG on reliability indices and power quality. The positive impacts included faster restoration and reduced voltage sags while the negative impacts could be sympathetic tripping, increased fuse blowing etc. In [11], the author discussed the intentional landing impacts of DG for reliability improvement.

\section{PORT HARCOURT NETWORK}

Port Hacourt Metropolis is a large city in the south-south geo political zone of Nigeria. It is the fastest growing city within the region in view of the oil exploration activities in the area, hence the rapid rate of growth in its load demands. The power distribution network as regards to Port Harcourt cannot be discussed in isolation from the prevailing shortfall in national power generation as the city still benefits from the national grid. Presently there is a clear mismatch between generation availability and load demand nationwide, thus, the current strict load shedding regimes that are observed. There are two numbers of transmission load centers in Port Harcourt complex (Port Harcourt main and town) with a total installated capacity of 222.5MVA while the total peak loads are $106.5 \mathrm{MW}$ (day) and 127.7MW (night) respectively. These were obtained under system/generation limitations. Total availability from the independent power producers (IPP) or distributed generation averages $60 \mathrm{MW}$ daily which is supplied to Port Harcourt metropolis. This distributed generation (IPP) includes Omoku and Trans-Amadi and Eleme. They all have their challenges to overcome. Outside the generation limitations transmission constraint, and distribution inadequacies; the actual load demand should be in the vicinity of $361.9 \mathrm{MW}$. There is presently, a gap of about 233.9MW, which must be bridged. In Port Harcourt metropolis, the installation distribution capacity is $444.5 \mathrm{MVA}$ on $33 \mathrm{kV}$ which translates to $355.6 \mathrm{MW}$ at operating power factor (PF) of 0.8 . Of course, the $33 \mathrm{kV}$ and $11 \mathrm{kV}$ distribution networks have not yet attained a state of perfection. There are technical challenges that need to be sorted out or eliminated but these are capital intensive.

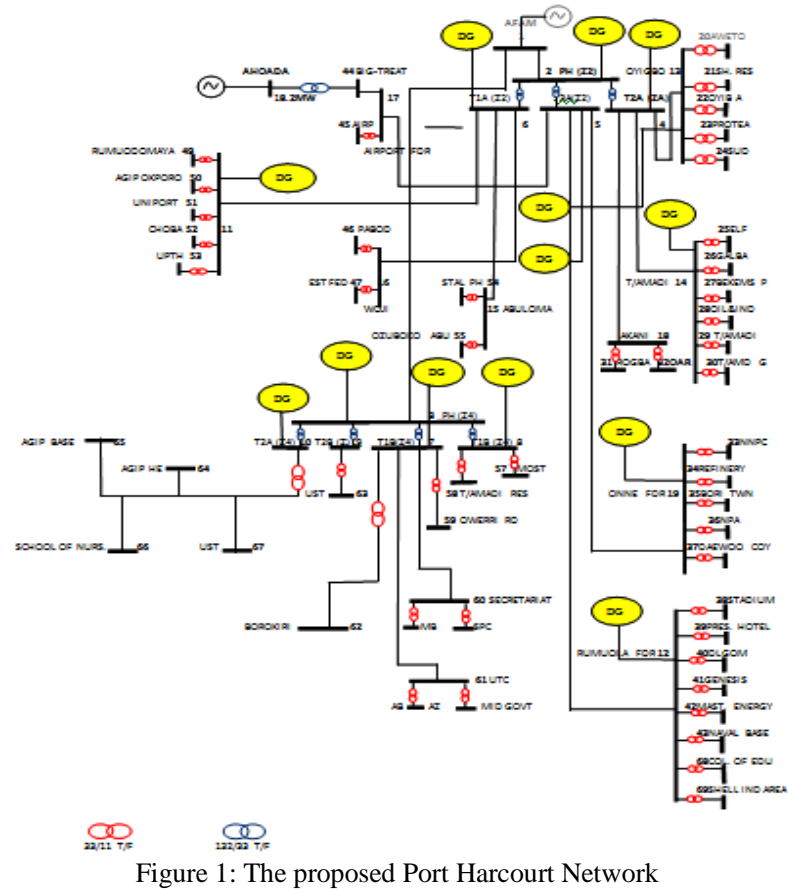

\section{A Distribution Network Impact Indices}

In order to evaluate and quantify the benefits of distributed generation technologies, suitable mathematical models along with distribution system models should be employed to run power flow calculations to arrive at indices of benefits. Among the many benefits, three major ones are considered: Voltage profile improvement, line loss reduction, line voltage stability. In this thesis, three indices are used to ascertain the best location of the DGs considering the voltage profile, real power losses and reactive power losses. These indices are defined as follows:

\section{$B$ Voltage Profile Improvement Index (VPII)}

DG installation normally results in improved voltage profile at various buses. The Voltage Profile Improvement Index quantifies the improvement in the voltage profile (VP) with the inclusion of DG. It is expressed as,

$V P I I=\frac{V P_{w D G}}{V P_{w o D G}}$

Based on this definition, the following attributes are:

VPII $>1$, DG is not beneficial,

$\mathrm{VPII}=1$, DG has no impact on the system voltage profile and

VPII < 1 DG has improved the voltage profile of the system.

Where, $\mathrm{VP}_{\mathrm{wDG}}, \mathrm{VP}_{\mathrm{woDG}}$ are the calculated amounts of the voltage profile of system substations with and without DG, respectively. The general expression for VP is given as,

$V P=\sum_{i=1}^{N} V_{i} L_{i} K_{i}$ with $\sum_{i=1}^{N} K_{i}=1$

Where, $\mathrm{V}_{\mathrm{i}}$ is voltage magnitude at bus $\mathrm{i}$ in per unit, $\mathrm{L}_{\mathrm{i}}$ is load represented as complex bus power at bus $\mathrm{i}$ in per unit, $\mathrm{K}_{\mathrm{i}}$ is weighting factor for bus $\mathrm{i}$, and $\mathrm{N}$ is total number of buses in the distribution system. Weighting factors are chosen based on the significance of different loads. As 
defined, the expression for VP provides an opportunity to quantify and aggregate the importance, amounts, and voltage levels at which loads are being supplied at various load busses in the system. This expression should be used only after making sure that the voltages at all the load busses are within allowable minimum and maximum limits, typically between 0.95 p.u. and 1.05 p.u. starting with a set of equal weighting factors, modifications can be implemented. Acceptable voltage profile can be selected after analyzing the simulation results which are repeatedly conducted after each weighting factor modification. It should be noted that if all load busses are equally weighted, the value of $\mathrm{Ki}$ is given as below:

$K_{1}=K_{2}=\cdots=K_{N}=\frac{1}{N}$

In this case, all the load buses are given equal importance. In reality, DG can be installed almost anywhere in the system.

In general, the lowest value of VPII implies the best location for installing DG in terms of improving voltage profile. The voltage profile expression in (3) recognizes the influences of the amount and importance of load at each bus. It allows the possibility of a low-load bus with important load to have a strong impact. In general, weighting factors are assigned based on the importance/criticality of load at each bus .

C Real and Reactive Power Loss Indices (ILP andILQ): Another major benefit offered by installation of DG is the reduction in electrical line losses [15]. By installing DG, line currents can be reduced, thus helping to reduce electrical line losses. The real and reactive power loss indices are

$I L P=\frac{\left[P_{L D G}\right]}{\left[P_{L}\right]}$
$I L Q=\frac{\left[Q_{L D G}\right]}{\left[Q_{L}\right]}$

Where, $P L D G$ and $Q L D G$ are the total real and reactive power losses of the distribution system after inclusion of DG. $P L$ and $Q L$ are the total real and reactive system losses without $\mathrm{DG}$ in the distribution system. The lower the values, the better the benefits in terms of loss reduction accrued to DGs locations and sizes.

Based on this definition:

ILP/ILQ $<1$ DG has reduced electrical line losses,

ILP/ILQ $=1$ DG has no impact on system line losses,

ILP/ILQ > 1 DG has caused more electrical line losses.

This index can be used to identify the best location to install DG which maximizes line loss reduction. Obviously, minimum value of ILP and ILQ corresponds to the best DG location scenario in terms of line loss reduction.

\section{RESULT}

The simulation of the work is done with MATLAB 7.9 and the result shows the best placement for each of the number of DG arrangement for the different sizes of DGs
Table 1: Summary of result for best placement of DGs

\begin{tabular}{|c|c|c|c|c|}
\hline Cases & $\begin{array}{l}\text { Number of } \\
\text { DGs }\end{array}$ & VPII & ILP & ILQ \\
\hline Case 1 & $\begin{array}{c}\text { Base unit } \\
\text { (without DG) }\end{array}$ & 1 & 1 & 1 \\
\hline Case 2 & 1 & 0.7424 & 2.1617 & 2.0143 \\
\hline Case 3 & 2 & 0.5455 & 1.2210 & 0.9091 \\
\hline Case 4 & 3 & 0.4091 & 1.3290 & 1.0103 \\
\hline Case 5 & 4 & 0.4848 & 1.3818 & 1.0057 \\
\hline Case 6 & 5 & 0.3030 & 1.3968 & 1.0532 \\
\hline Case 7 & 6 & 0.2879 & 0.3346 & 0.2723 \\
\hline Case 8 & 7 & 0.1061 & 0.1288 & 0.1051 \\
\hline Case 9 & 8 & 0.1061 & 0.1599 & 0.1247 \\
\hline Case 10 & 9 & 0.1061 & 0.1363 & 0.1079 \\
\hline Case 11 & 10 & 0.1061 & 0.1375 & 0.1090 \\
\hline Case 12 & 11 & 0.1061 & 0.1377 & 0.1160 \\
\hline Case 13 & 12 & 0.1061 & 0.2987 & 0.2256 \\
\hline Case 14 & $\begin{array}{l}2(25 \mathrm{MW}), \\
3(25 \mathrm{MW}), \\
4(25 \mathrm{MW}), \\
5(25 \mathrm{MW}), \\
6(25 \mathrm{MW}), \\
7(25 \mathrm{MW}), \\
8(25 \mathrm{MW}), \\
10(25 \mathrm{MW}), \\
11(25 \mathrm{MW}), \\
12(25 \mathrm{MW}), \\
13(10 \mathrm{MW}), \\
14(10 \mathrm{MW}), \\
19(10 \mathrm{MW})\end{array}$ & 0.07576 & 0.05023 & 0.06001 \\
\hline
\end{tabular}

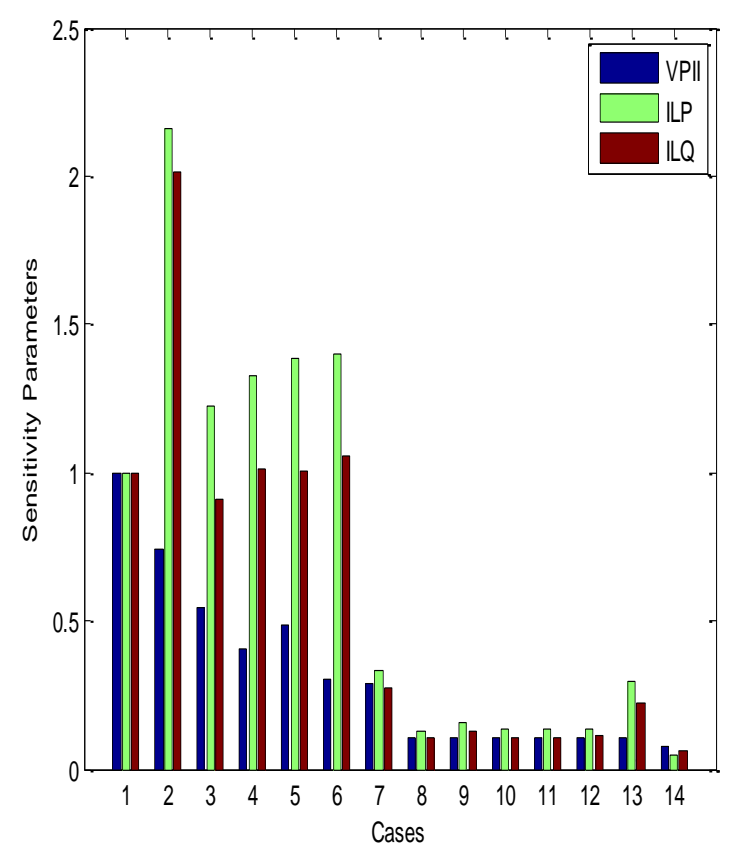

Figure 1: Comparison of the reliability parameters

\section{DISCUSSION}

The results for the reliability analysis for the different reliability parameter was considered, obtained and compared. From the result in Table 1 and Figure 1, it will be unreliable to distribute the DGs along 2-5 Buses as compared to the base unit (without DG) as compared to the VPII and ILQ. Considering ILP, which gave a progressive decrease and a sharp increase when DGs are distributed to four Buses, VPII remained constant (0.1061) from the distribution of the DGs among six Buses to distribution of 
DGs to twelve Buses. The best VPII was seen when the thirteen available DGs are distributed among thirteen Buses. At twelve Buses DGs distribution, a sharp increase was seen for ILP and ILQ showing that it will be inappropriate to allocate the DGs to twelve Buses. The best overall performance was seen when DGs are placed in thirteen Buses which gave a VPII of 0.07576 , ILP of 0.05023 and ILQ of 0.06001 .

\section{CONCLUSION}

Reliability study was carried out on the network to know which network can be considered best based on the voltage violations, real and reactive power losses. The work done shows that DG can be used to solve the problem of power supply inadequacy in Port Harcourt. With the current rate at which power demand is increasing, the present network cannot carry the power demand of the area (Port Harcourt area). With the introduction of large DGs, the network can withstand the present demand of the area with more loads added. One of the greatest problems encountered when trying to synchronise a DG into a network was the best location or place to introduce the DG. The total number of DGs that can be obtained from both Omoku and TransAmadi is of ten $25 \mathrm{MW}$ gas turbines and three $10 \mathrm{MW}$ gas turbines. From the study, the DGs are placed based on their sizes to the different scenarios considered. After the study it was observed that it will be proper for the DGs to be place at Buses 2(PH Z2)(25MW), 3(PH Z4)(25MW), 4(TIA Z2)(25MW), 5(T2A Z2)(25MW), 6(T3A Z2)(25MW), 7(TIB Z4)(25MW), 8(TIA Z4)(25MW), 10(T2A Z4)(25MW), 11(Rumuodomaya)(25MW), 12(Rumuola feeder)(25MW), 13(Oyigbo)(10MW), 14(Trans-Amadi)(10MW) and 19(Onne feeder)(10MW) for better performance. This also showed that it will be more preffarable to distribute the DGs closer to the load centers.

\section{REFERENCES}

[1] Port Harcourt Distribution Company of Nigeria (Disco 2015)

[2] R. J Rusch, D. L Metz,. (1999). "Customer oriented reliability indices and data collection,"Rural Electric Power Conference, 1999 , vol., no., pp.A1/1-A1/8.

[3] A. Warren, (1999) "A suvey of Distribution Reliability Measurement Practice in US Power Delivery", IEEE Transactions of vol 14, no 1, pp250-257

[4] A. A. Chowdhury, S. K. Agarwal, D.O Koval, (2003). "Reliability modeling of distributed generation in conventional distribution systems planning and analysis," IndustryApplications, IEEE Transactions on, vol.39, no.5, pp. 1493-1498.

[5] R. E. Brown, L. A. Freeman, (2001). "Analyzing the reliability impact of distributed generation," Power Engineering Society Summer Meeting, 2001. IEEE, vol.2, no., pp.1013-1018.

[6] M. Fotuhi-Firuzabad, A. Rajabi-Ghahnavie, (2005). "An Analytical Method to Consider DG Impacts on Distribution System Reliability," Transmission and Distribution Conference and Exhibition: Asia and Pacific, 2005 IEEE/PES , vol., no., pp.16.

[7] S.Y. Yun, J.C. Kim, J.F. Moon, C.H. Park, S.M. Park, M.S. Lee, (2003). "Reliability evaluation of radial distribution system considering momentary interruptions," Power Engineering Society General Meeting, 2003, IEEE , vol.1, no., pp. 485 Vol. 1, 13-17.

[8] H. Falaghi, M.R Haghifam, (2005). "Distributed Generation Impacts on Electric Distribution Systems Reliability: Sensitivity Analysis," Computer as a Tool, 2005.EUROCON 2005.The International Conference on, vol.2, no., pp.1465-1468.

[9] C.L. Borges, D. M. Falcao, (2003). "Impact of distributed generation allocation and sizing on reliability, losses and voltage profile," Power Tech Conference Proceedings,IEEE Bologna vol.2, no., pp. 5 pp. Vol.2-, 23-26.

[10] T.E McDermott, R.C Dugan, (2002) "Distributed generation impact on reliability and power quality indices," Rural Electric Power Conference, 2002.2002 IEEE, vol., no., pp.D3-D3-7.

[11] P.P Barker, R.W. De Mello, (2000). "Determining the impact of distributed generation on power systems in Radial distribution systems," Power Engineering Society Summer Meeting, 2000. IEEE, vol .3, no., pp.1645-1656 vol. 3 . 